\title{
Application of Competitive ELISA Method for Estimation of Urinary Aflatoxin M1 Level
}

Yong-Dae Kim* and Heon Kim

\author{
Department of Preventive Medicine and Medical Research Institute, College of Medicine, Chungbuk National University, Cheongju 361-763, \\ Korea
}

Received January 2, 2013 /Revised February 5, 2013 /Accepted February 5, 2013

\begin{abstract}
We compared the efficacy of the competitive ELISA method for measuring the level of urinary aflatoxin M1 (AFM1) with that of the HPLC-fluorescence detector (HPLC-FLD) method. The recovery rate of AFM1 with the ELISA method was $105 \%$ (73-124\%), and the coefficient of variation of the analysis was $6.85 \%$. The ELISA method showed a $0.20 \mathrm{pg} / \mathrm{ml}$ and $0.62 \mathrm{pg} / \mathrm{ml}$ limit of detection and limit of quantitation, respectively. In correlation analysis, the two methods showed a very strong and statistically significant correlation $(R=0.96, p<0.01)$. However, in spite of the strong correlation, the ELISA method tended to overestimate the urinary AFM1 concentration compared to the HPLC-FLD method. These results suggest that the competitive ELISA method may be a useful technique for measuring the AFM1 level in high-throughput urine samples, but it needs to be corrected with a regression equation from regression analysis with the HPLC-FLD method.
\end{abstract}

Key words : Urinary aflatoxin M1, competitive ELISA, HPLC-fluorescence detector (HPLC-FLD)

\section{서 론}

Aspergillus 속 곰팡이가 주로 생산하는 아플라톡신은 곰 팡이의 2 차 대사물질로서 간에 대한 독성, 특히 발암성이 매 우 강한 것으로 알려져 있다 $[4,11]$. 옥수수, 땅콩, 면실과 같 은 곡류, 두류 등의 각종 농산물에서 검출되며 보통의 식품 가공이나 살균처리로는 파괴되지 않는다. 지금까지 화학적 구조가 서로 다른 18종의 아플라톡신이 확인되었으며 thin layer chromatography (TLC)에 의해 자외선 하에서 발현되 는 형광의 색에 따라서 B (Blue)군, G (Green)군으로 크게 분류한다[6, 11]. 자연상태에서는 아플라톡신 B1 (AFB1), B2, $\mathrm{G} 1, \mathrm{G} 2$ 형태로 주로 존재하며, 이 중에서 가장 독성이 강하 고 발생빈도가 높은 것은 $\mathrm{AFB} 1$ 이다[8]. AFB1은 체내로 유 입되면 위장관으로 빠르게 흡수되어 간에 도달하며 그 곳에 서 cytochrome P450 효소에 의해 아플라톡신 M1 (AFM1)을 비롯한 다양한 종류의 물질로 대사되는 것으로 알려져 있다 [8]. AFM1은 사람과 동물의 소변, 유즙, 혈액 등에 존재하는 데[8], 사람의 경우에는 $\mathrm{AFB1}$ 의 섭취 정도에 따라 $\mathrm{AFM1}$ 으 로의 전환률이 달라질 수 있다. 즉, 식이를 통한 $\mathrm{AFB1}$ 의 일

\footnotetext{
*Corresponding author

Tel : +82-43-261-2845, Fax : +82-43-274-2965

E-mail : ydkim@chungbuk.ac.kr

This is an Open-Access article distributed under the terms of the Creative Commons Attribution Non-Commercial License (http://creativecommons.org/licenses/by-nc/3.0) which permits unrestricted non-commercial use, distribution, and reproduction in any medium, provided the original work is properly cited.
}

일 노출량이 높은 경우는 섭취된 양의 $1.4 \sim 1.5 \%$, 일일 노출 량이 낮은 경우는 약 $5 \%$ 정도가 요중 $\mathrm{AFM1}$ 형태로 배설된 다고 알려져 있다[12].

체내에 흡수된 AFB1은 대부분이 다른 물질로 대사되기 때 문에 요중으로 배설되는 $\mathrm{AFB} 1$ 의 농도는 $\mathrm{AFB1}$ 의 노출량을 제 대로 반영하지 못한다. 따라서, AFB1의 노출을 평가할 수 있는 적절한 지표를 개발하기 위한 노력이 지속적으로 이루어져 왔다. 선행 연구 결과에 따르면 요로 배출되는 AFB1의 대사체 의 양과 식품 중 $\mathrm{AFB1}$ 의 오염정도를 분석하여 상관관계를 분 석한 결과, $\mathrm{AFB1}$ 의 대사체인 aflatoxin-N7-guanine과 AFM1 과의 높은 상관관계를 확인하였으며, 그 중 AFM1이 aflatoxin-N7-guanine의 두 배 정도 많이 존재하여 시료를 분석하기 에 더욱 용이한 지표라고 보고하였다[9]. 따라서 AFB1의 노출 정도를 파악하는데 있어서 요중 AFM1의 농도가 상대적으로 좋은 지표가 될 수 있을 것으로 예상된다.

지금까지 요중 AFM1의 농도는 주로 면역친화컬럼(Immuno affinity column)을 이용한 전처리와 결합된 HPLC-FLD방법 이나 HPLC-MS의 방법이 주로 이용되고 있으나 방법의 특성 상 시간과 비용에 대한 부담이 매우 커서 대규모 시료의 분석 에 이용되는 데에는 많은 제약이 있었다 $[2,3,12]$. 따라서, 이러 한 단점을 보완할 수 있는 새로운 측정방법의 개발이 절실한 상황이다.

본 연구에서는 competitive ELISA가 요중 AFM1 농도 측정 에 적합한 방법인지를 판단하기 위하여 HPLC-FLD 방법과의 특성을 비교, 평가해 보고자 하였다. 


\section{재료 및 방법}

\section{대상자}

2011년 실시한 식약청의 유해물질 안전관리 통합노출평가 기반 연구사업의 일환으로 전국의 성인을 대상으로 확률표본 추출하여 수집한 시료 중 HPLC 방법으로 요중 AFM1이 검출 된 20명의 소변 시료를 대상으로 ELISA 방법을 이용하여 요중 AFM1의 농도를 측정하였으며 이를 HPLC-FLD 방법에 의한 결과와 비교 평가하였다.

\section{소변시료 농축}

competitive ELISA 분석을 위한 소변은 원심분리기(Hanil, Union 32R Plus)를 이용하여 $3,000 \mathrm{~g}$ 로 15 분간 원심분리 하였 다. 상층액 $2 \mathrm{ml}$ 를 원심진공농축기(Hanil, Modul 4080C)로 $80^{\circ} \mathrm{C}$ 에서 약 $500 \mu 1$ 가 될 때까지 농축시켰다. 남은 용액을 $10,000 \mathrm{rpm}$ 으로 10 분 동안 원심분리한 후 상층액 $270 \mu 1$ 에 10 $X \mathrm{PBS}$ 를 가하여 총 $300 \mu \mathrm{l}$ 를 만들었다. 농축배율은 농축 전후 에 소변의 무게를 측정하여 산출하였다. 한편, HPLC-FLD 분 석 방법으로 요중 $\mathrm{AFM1}$ 의 농도를 측정하기 위하여 소변 시료
$3 \mathrm{ml}$ 를 면역친화컬럼(VICAM, USA)에 통과시킨 후 $10 \mathrm{ml}$ 의 PBS로 세척하였다. 세척이 끝나면 methanol과 acetonitrile이 2:3의 비율로 혼합된 용매 $0.5 \mathrm{ml}$ 로 먼저 추출한 후 동량의 물로 다시 한번 추출하여 최종 $1 \mathrm{ml}$ 의 용액을 만든 후 $\mathrm{HPLC}$ 로 분석하였다(Fig. 1).

\section{경쟁적 효소면역측정법(Competitive ELISA)}

경쟁적 효소면역측정법으로 요중 $\mathrm{AFM1}$ 의 농도를 산출하 기 위하여 이미 상품화 되어있는 AFM1용 kit (Immunolab $\mathrm{GMBH}$, Kassel, Germany)를 사용하였다. 간략히 방법을 기술 하면, 항원이 부착되어 있는 well에 농축한 소변시료와 표준시 료 $0 \mathrm{pg} / \mathrm{ml}, 10 \mathrm{pg} / \mathrm{ml}, 50 \mathrm{pg} / \mathrm{ml}, 100 \mathrm{pg} / \mathrm{ml}$ 를 100 pl씩 넣고 곧바로 1 차 항체를 $50 \mu 1$ 씩 넣었다. 잘 혼합하여 실온에서 60 분 간 방치한 후 well 내의 혼합물을 버리고 세척용액으로 3 회 세척하였다. 세척 후 conjugate solution을 well 당 $100 \mathrm{\mu l}$ 씩 넣고 실온에서 다시 60 분간 반응 시켰다. 반응이 끝난 후 well 내의 혼합물을 버리고 세척용액으로 3회 세척하였으며 세척 이 끝난 plate에 기질용액을 well 당 $100 \mu 1$ 씩 넣고 빛을 차단한 실온 상태에서 5 분간 방치하였다. 반응 후 stop solution을 100
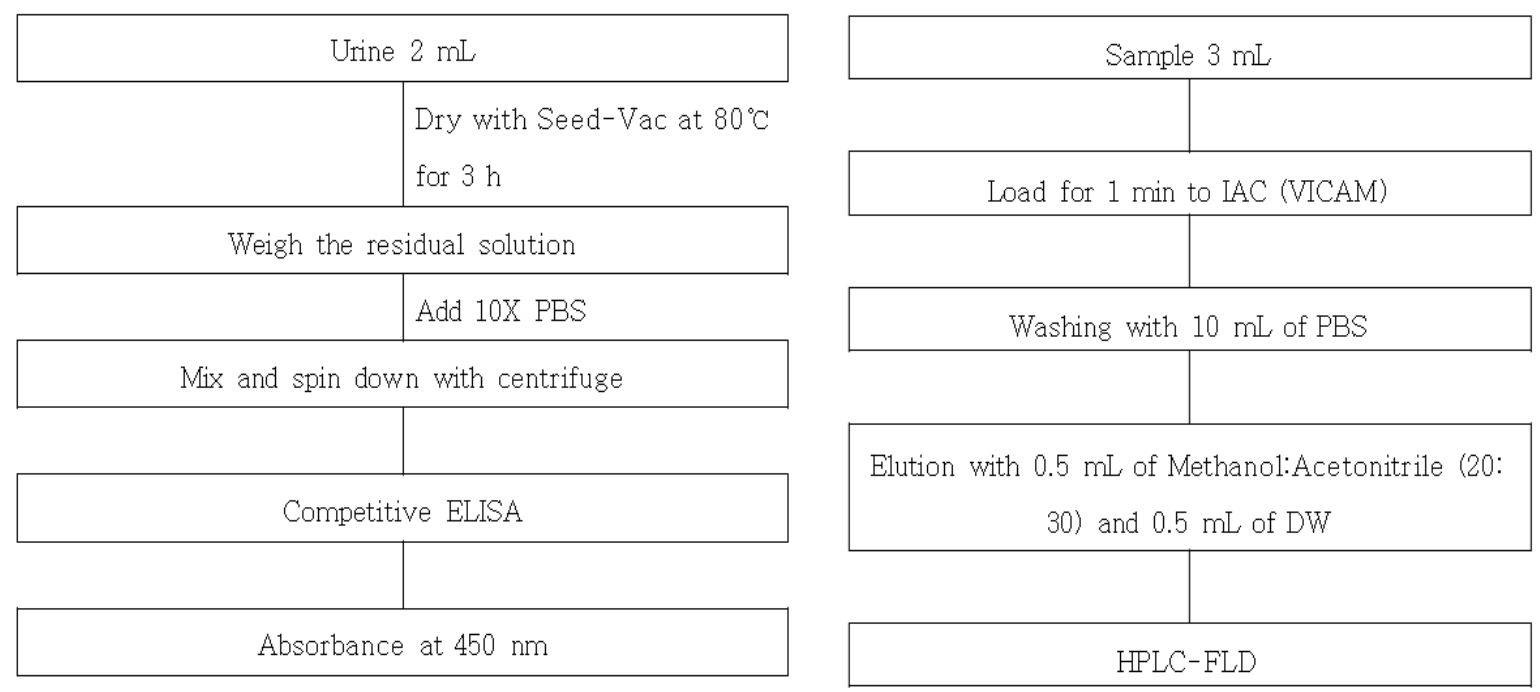

Fig. 1. Flow charts of pre-treatment of urine for competitive ELISA and HPLC-FLD methods.

Table 1. Analytic condition of HPLC-FLD for urinary AFM1 measurement

\begin{tabular}{ll}
\hline Condition & \\
\hline Column & Tosoh ODS 80TM, 150 x 4.4 mm \\
Mobile phase & $50 \% \mathrm{MeOH}+4 \mathrm{M}$ Nitric acid $(350 \mu \mathrm{l} / \mathrm{l})+\mathrm{KBr}(119 \mathrm{mg} / \mathrm{l})$ \\
Wave length & $353 \mathrm{~nm}, 432 \mathrm{~nm}$ \\
Flow rate & $1 \mathrm{ml} / \mathrm{min}$ \\
Retention time & $10 \mathrm{~min}$ \\
Injection volume & $100 \mu \mathrm{l}$ \\
Column temp. & Room temp. \\
KOBRA Cell & R-Biopharm Rhone Ltd \\
\hline
\end{tabular}



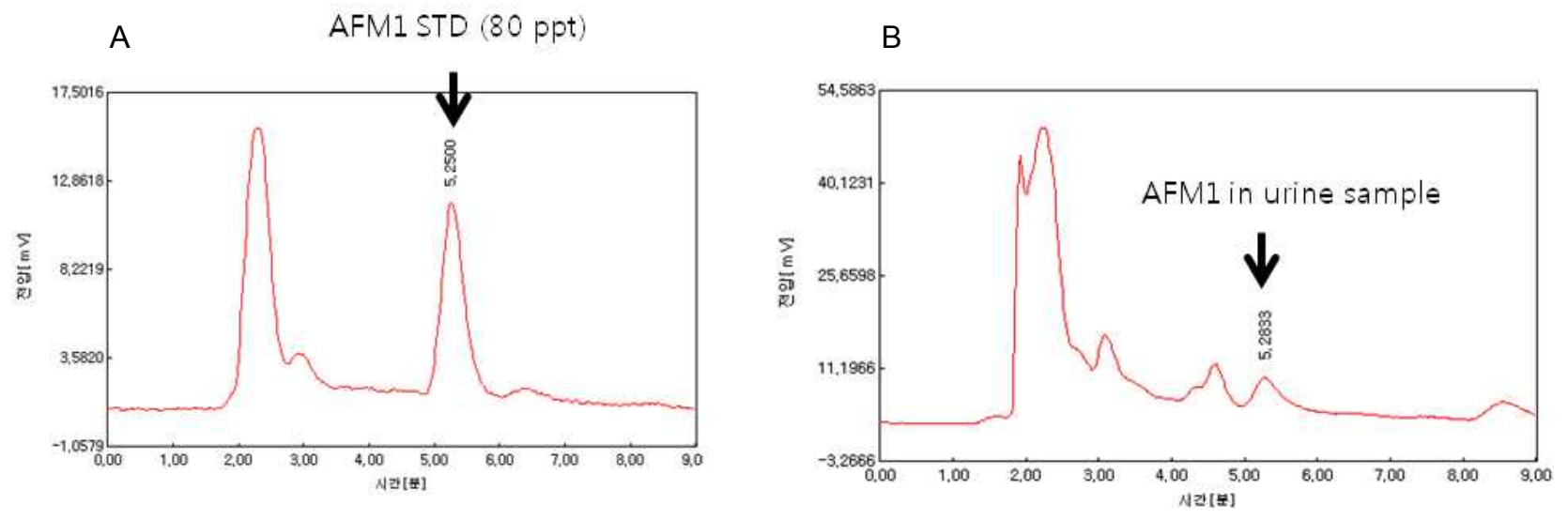

Fig. 2. Chromatograms of AFM1 standard and sample in HPLC-FLD analysis. A: AFM1 standard (80 pg/ml), B: AFM1 in urine sample.

씨씩 넣어주어 반응을 종료하고, $450 \mathrm{~nm}$ (reference wavelength $620 \mathrm{~nm}$ ) 파장에서 흡광도를 측정하였다. 측정된 흡광 도를 환산하여 요중 $\mathrm{AFM1}$ 농도를 산출하였다. 측정된 시료의 흡광도가 표준시료 $0 \mathrm{pg} / \mathrm{ml}$ 의 흡광도보다 높은 경우는 불검 출 시료로 판정하였다.

\section{HPLC-FLD 분석}

$\mathrm{HPLC}$ 를 이용한 요중 AFM1의 측정은 Neal 등의 방법 [9]을 다소 수정하여 사용하였다. 펌프(Model 305, Gilson) 와 자동분주기(SIL-10AD, Shimadzu), 형광검출기(RF-20A, Shimadzu)로 구성된 HPLC system과 Tosoh ODS column 을 사용하여 분석하였다. 이동상 용액은 $50 \%$ methanol과 4 M Nitric acid (350 $\mu \mathrm{l} / \mathrm{l}), \mathrm{KBr}(119 \mathrm{mg} / \mathrm{l})$ 혼합액을 사용하 였다. 속도는 분당 $1 \mathrm{ml}$ 였고 주입용량은 $100 \mu \mathrm{l}$, 형광 분석 파장은 $353 \mathrm{~nm}, 432 \mathrm{~nm}$ 를 이용하였다. 분석 감도를 높이 기 위하여 KOBRA cell (R-Biopharm Rhone Ltd, UK)을 부 착하여 분석하였다(Table 1, Fig. 2).

\section{통계분석}

통계분석은 윈도우용 SPSS (Version 12.0)를 사용하였다. 두 방법간의 관련성을 파악하기 위하여 Pearson 상관분석을 이용하였고 $p$ 값이 0.05 이하인 경우를 유의한 것으로 판정 하였다.

\section{결과 및 고찰}

요중 AFM1 농도를 측정하는 방법은 지금까지 HPLC-FLD 방법이나, HPLC-MS 등의 방법이 주로 이용되고 있으나 검출 율이 비교적 낮고 높은 분석 비용 및 시간 소모가 많아서 이를 보완할 수 있는 방법의 개발 노력이 지속적으로 진행되고 있 다 $[2,3,12]$. 이러한 이유 때문에 일반인구집단을 대상으로 한
Table 2. Recovery rate of urinary AFM1 and coefficient of variance on competitive ELISA method

\begin{tabular}{ccc}
\hline $\begin{array}{c}\text { Spiked AFM1 } \\
(\mathrm{pg} / \mathrm{ml})\end{array}$ & $\begin{array}{c}\text { Recovered AFM1 } \\
(\mathrm{pg} / \mathrm{ml})\end{array}$ & $\begin{array}{c}\text { recovery rate } \pm \mathrm{CV} \\
(\%)\end{array}$ \\
\hline 2.5 & $2.97 \pm 0.66$ & $119.10 \pm 8.72$ \\
5 & $3.63 \pm 0.15$ & $72.64 \pm 4.78$ \\
10 & $12.44 \pm 2.35$ & $124.39 \pm 7.06$ \\
\hline Average & & $105.37 \pm 6.85$ \\
\hline
\end{tabular}

Table 3. LOD and LOQ levels of urinary AFM1 on competitive ELISA method

\begin{tabular}{lc}
\hline & AFM1 $(\mathrm{pg} / \mathrm{ml})$ \\
\hline Limit of detection (LOD) & 0.20 \\
Limit of quantitation (LOQ) & 0.62 \\
\hline
\end{tabular}

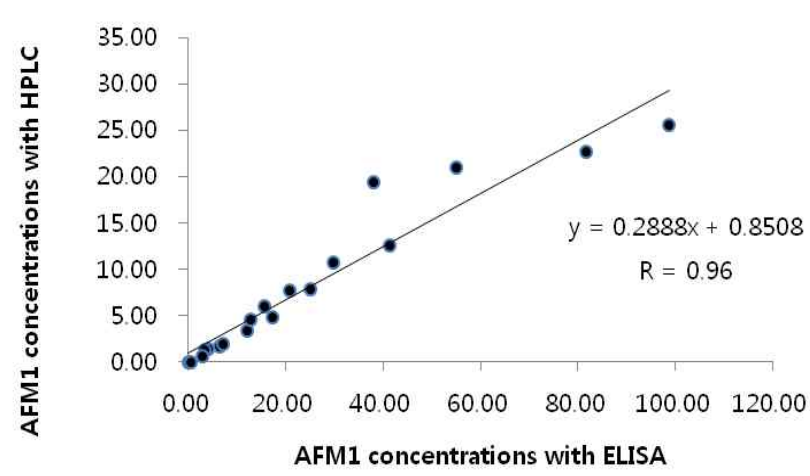

Fig. 3. Relationship between urinary AFM1 concentrations with HPLC-FLD and competitive ELISA methods.

요중 AFM1 농도를 조사한 역학조사는 많지 않은 실정이며, 식품섭취를 통한 설문조사 자료로 아플라톡신의 노출을 추정 한 연구가 대부분이다 $[1,5,6,10]$. 김현정 등은 2009년 보고한 논문에서 competitive ELISA를 이용한 방법은 검출감도가 매 우 높으면서도 측정방법이 간단해서 매우 유용한 분석방법임 
을 보고한 바 있다[7]. 본 연구의 결과에서도 요중 AFM1 농도 측정에 이용한 competitive ELISA 방법의 검출한계는 0.2 $\mathrm{pg} / \mathrm{ml}$, 정량한계는 $0.62 \mathrm{pg} / \mathrm{ml}$ 로 나타나 기존의 HPLC-FLD 방법에 비해 뒤지지 않는 매우 민감한 방법임이 확인되었다 (Table 3). 또한, ELISA를 이용한 요중 AFM1의 측정방법은 첨가한 표준용액의 농도에 따라 다소 차이는 보였으나 평균적 으로 $105.37 \%$ 의 높은 회수율을 보여주었으며 반복 측정 시의 변이계수도 평균 $6.85 \%$ 를 나타내 매우 안정적인 결과를 보여 주었다(Table 2). 김 등의 연구[7]에 따르면 본 연구에서와 동 일한 competitive ELISA 방법을 이용하여 요중 AFM1의 농도 를 측정한 결과, 회수율과 변이계수가 각각 $139 \%$ 와 $14.8 \%$ 였다 고 보고하였으며, 검출한계도 $10 \mathrm{pg} / \mathrm{ml}$ 라고 보고하여 본 연구 에서 사용된 방법이 상대적으로 민감하면서도 안정적인 방법 임을 알 수 있었다. 이와 같은 차이는 그 동안 AFM1에 특이적 으로 반응하는 1 차 항체의 개발이 지속적으로 이루어졌기 때 문에 두 연구에서 사용된 ELISA kit의 민감도 차이 때문일 가능성이 크겠지만, 그와 더불어 두 연구에서 사용된 전처리 과정의 차이 때문일 가능성도 배제할 수 없다. 김 등의 연구[7] 에서는 C18 cartridge column을 이용한 정제 방법을 이용한 반면, 본 연구에서는 소변시료를 농축하기 위한 방법으로 진 공건조를 이용하였다. 일반적으로 면역친화컬럼을 비롯한 컬 럼 정제 방법은 단시간 내에 특정 물질만을 농축시킬 수 있다 는 장점은 있으나 세척과 추출을 반복하는 과정에서 원하는 물질을 일부 손실할 수 있는 단점이 있기 때문이다. 본 연구에 서 사용한 진공건조 방법은 컬럼 방식에 비해 상대적으로 많 은 처리 시간이 소요되고 특정물질만을 정제하기는 어려우나 소변을 그대로 농축시키기 때문에 특정물질의 손실이 거의 없어 극소량의 시료분석을 위한 전처리에 보다 적합한 방법이 될 수 있다.

본 연구에서 분석한 소변 시료는 모두 20개로 다소 적은 양이기는 하나 이 중 19 개의 시료에서 $\mathrm{AFM} 1$ 이 검출되어 $95 \%$ 의 검출율을 나타내었다. 이는 김 등[7]의 연구 결과 $(95.9 \%)$ 와 거의 유사한 것으로 HPLC 방법에서 보고된 $40 ~ 70 \%$ 의 검출율 보다는 월등히 높은 수준임을 알 수 있다. 이상의 결과를 종합 해 볼 때, 본 연구에서 사용된 진공건조에 의한 전처리 방법과 competitive ELISA 방법을 이용한 요중 AFM1의 분석은 안정 적이면서도 민감성이 뛰어난 우수한 방법으로 판단되었다.

ELISA를 이용한 요중 AFM1 농도와 기존의 HPLC-FLD 방 법을 이용하여 측정한 농도와의 관련성을 파악하기 위하여 두 측정값 사이의 산점도를 그리고 상관분석을 시행하였다. 그 결과, 두 방법을 이용한 측정값 사이에는 상관계수 0.96 $(p<0.01)$ 의 매우 높은 관련성이 있음이 확인되었다(Fig. 3). 그 러나 이처럼 높은 관련성에도 불구하고 두 측정치에 대한 회 귀식 'HPLC를 이용한 측정치 $=0.29 \times$ ELISA를 이용한 측정치 $+0.85^{\prime}$ 에서 보는 바와 같이 ELISA를 이용하여 측정한 AFM1 농도가 HPLC로 측정한 값에 비해 상대적으로 높음을 알 수
있다. 이러한 결과는 ELISA의 특성상 AFM1과 구조적으로 매 우 유사한 다른 종류의 아플라톡신에 대한 교차반응 때문일 가능성이 크다. 특히, $\mathrm{AFB} 1$ 은 $\mathrm{AFM} 1$ 과 수산기 $(\mathrm{OH})$ 하나의 차이를 보이는 구조이고 $\mathrm{AFM2}$ 는 $\mathrm{AFM} 1$ 이 가진 이중결합 하 나가 단일결합으로 치환된 형태여서 상호간에 구조적으로 매 우 유사한 특징을 가지고 있다. HPLC 분석은 미세한 구조적 차이도 감별해 낼 수 있는 능력이 있는 반면, ELISA에서의 항원 항체 반응은 그런 능력이 상대적으로 떨어지기 때문에 이들에 의한 교차반응 가능성이 있고 이를 극복하기 위한 새 로운 항체의 개발이 지속적으로 이루어져야 할 것이다.

요중 AFM1의 농도가 아플라톡신의 노출을 평가할 수 있는 좋은 지표임에도 불구하고 아직까지 우리나라에서 요중 AFM1 농도에 대한 연구는 거의 없는 실정이다. 그러한 이유 는 앞서 기술한 바와 같이 기존의 방법들이 많은 시간과 돈이 소요됨에도 불구하고 검출율이 높지 않기 때문이다. 그러한 관점에서 볼 때 competitive ELISA 방법은 그 활용 가치가 매우 높다고 할 수 있다. 특히, 대규모의 시료를 분석하는 경우 에 매우 효율적인 방법이 될 것으로 기대된다. 다만, 교차반응 등의 이유로 실제 농도보다 과평가되는 경향이 있음을 감안하 여 ELISA 방법에 의한 결과를 해석할 때는 이 부분에 대한 충분한 고려가 동반되어야 할 것으로 판단된다.

\section{감사의 글}

이 논문은 2012년도 식품의약청의 지원을 받아 수행된 연구 사업임(10162KFDA994).

\section{References}

1. Applebaum, R. S., Brackett, R. E., Wiseman, D. W. and Marth, E. H. 1982. Aflatoxin: oxicity to dairy cattle and occurrence in milk and milk products. A Review J Food Prot 45, 752-777.

2. Cheng, Z., Root, M., Ran, W., Chen, J. and Campbell, T. C. 1997. Use of an improved method for analysis of urinary aflatoxin M1 in a survey of Mainland China and Taiwan. Cancer Epidem Biomarker Prev 6, 523-529.

3. Everley, R. A., Ciner, F. L., Zhan, D., Scholl, P. F., Groopman, J. D. and Croley, T. R. 2007. Measurement of aflatoxin and aflatoxin metabolites in urine by liquid chromatographytandem mass spectrometry. J Anal Toxicol 31, 150-156.

4. Hu, W. G., Tien, C. C., Wang, Y. H., Ting, T. Y., Fong, Y. C., Loung, Y. T. and Huang, S. S. 1983. Urinary excretion of aflatoxin M1 in inhabitants of region with high liver cancer incidence in Guangxi. Hygiene Invest 27, 152-154.

5. Jonsyn-Ellis, F. E. 2001. Seasonal variation in exposure frequency and concentration levels of aflatoxins and ochratoxins in urine samples of boys and girls. Mycopathologia 152, $35-40$. 
6. Kim, E. K., Shon, D. H., Ryu, D., Park, J. W., Hwang, H. J. and Kim, Y. B. 2000. Occurrenceofaflatoxin M1 in Korean dairy products determined by ELISA and HPLC. Food Addit Contam 17, 59-64.

7. Kim, H. J., Kwak, B. Y. and Shon, D. H. 2009. Detection of Aflatoxin M1 in Human and Porcine Urine and Its Risk Assessment. Korean J Food Sci Technol 41, 215-221.

8. Leong, Y. H., Latiff, A. A., Ahmad, N. I. and Rosma, A. 2012. Exposure measurement of aflatoxins and aflatoxin metabolites in human body fluids. A short review. Mycotoxin Res 28, 79-87.

9. Neal, G. E., Eaton, D. L., Judah, D. J. and Verma, A. 1998. Metabolism and toxicity of aflatoxins M1 and B1 in human-derived in vitro systems. Toxicol Appl Pharmacol 151, $152-158$
10. Park, J. W., Kim, E. K. and Kim, Y. B. 2004. Estimation of the daily exposure of Koreans to flatoxin B1 through food consumption. Food Addit Contam 21, 70-75.

11. Wogan, G. N., Kensler, T. W. and Groopman, J. D. 2012. Present and future directions of translational research on aflatoxin and hepatocellular carcinoma. A review Food Addit Contam Part A Chem Anal Control Expo Risk Assess 29, 249-257.

12. Zarba, A., Wild, C. P., Hall, A. J., Montesano, R., Hudson, G. J. and Groopman, J. D. 1992. Aflatoxin M1 in human breast milk from The Gambia, west Africa, quantified by combined monoclonal antibody immunoaffinity chromatography and HPLC. Carcinogenesis 13, 891-894.

\section{초록 : ELISA 방법을 이용한 요중 아플라톡신 M1 측정}

김용대*·김헌

(충북대학교 의과대학 예방의학교실 및 의학연구소)

본 연구는 요중 아플라톡신 M1 (AFM1)의 농도를 측정할 수 있는 competitive ELISA 방법의 특성을 HPLC-fluorescence detector (HPLC-FLD) 방법과 비교하여 평가하였다. ELISA 방법에서의 AFM1의 회수율은 $105 \%$ (73-124\%)였고 측정의 변이계수는 $6.85 \%$ 로 나타났다. ELISA 방법에서의 검출한계와 정량한계는 각각 0.20 $\mathrm{pg} / \mathrm{ml}$ 과 $0.62 \mathrm{pg} / \mathrm{ml}$ 로 조사되었으며, 두 방법을 이용하여 측정한 요중 AFM1 농도는 상관계수 0.96의 매우 높은 상관성이 있는 것으로 확인되었다( $p<0.01)$. 그러나, 이렇게 높은 상관성에도 불구하고, ELISA 방법을 이용한 요중 AFM1의 농도는 HPLC-FLD 방법으로 측정한 값에 비해 상대적으로 높게 나타나는 경향을 보여 ELISA를 이용한 방법이 단시간에 많은 시료를 분석할 수 있는 장점은 있으나 그 결과는 HPLC-FLD 방법을 이용해서 얻은 회귀식 을 이용하여 보정을 한 후 제시할 필요가 있는 것으로 판단된다. 